$\mathbb{P}$ periodica polytechnica

Civil Engineering

58/3 (2014) 203,216

doi: $10.3311 /$ PPci.7460

http://periodicapolytechnica.org/ci

Creative Commons Attribution (1)

RESEARCH ARTICLE

\section{Magnetic charged system search for structural optimization}

\author{
Ali Kaveh / Ali Zolghadr
}

Received 2014-04-03, accepted 2014-07-07

\begin{abstract}
In this paper the Magnetic Charged System Search algorithm is applied to structural optimization. This algorithm uses the Biot-Savar law of electromagnetism to incorporate magnetic forces into the already existing Charged System Search algorithm and thus can be considered as an extension of it. Each search agent exerts magnetic forces on other agents based on the variation of its objective function value during its last movement. This additional force provides some additional information and enhances the performance of the Charged System Search. The efficiency of the Magnetic Charged System Search is examined by application of this algorithm to four structural optimization problems. The results are compared to those of CSS and some of the methods available in the literature.
\end{abstract}

\section{Keywords}

Optimal design of structures - Charged System Search (CSS) . Magnetic Charged System Search (MCSS) · Trusses · Frames

\section{Ali Kaveh}

Centre of Excellence for Fundamental Studies in Structural Engineering, School of Civil Engineering, Iran University of Science and Technology, Narmak, P.O. Box 16846-13114, Iran

e-mail: alikaveh@iust.ac.ir

\section{Ali Zolghadr}

Centre of Excellence for Fundamental Studies in Structural Engineering, School of Civil Engineering, Iran University of Science and Technology, Narmak, P.O. Box 16846-13114, Iran

\section{Introduction}

Optimization algorithms can be roughly divided into two main groups consisting of mathematical programming techniques and meta-heuristic methods. Many different mathematical programming techniques have been proposed and developed during the past decades. Linear programming, convex programming, integer programming, quadratic programming, and dynamic programming are some of these approaches that have been utilized for optimization problems. These methods usually provide accurate solutions; however, most of them need the gradient information of the objective function, and are dependent on the initial points.

In order to address these shortcomings meta-heuristic algorithms are developed. These algorithms are meant to find some sub-optimal solutions in an affordable time and are usually inspired from natural phenomena. Genetic Algorithms (GA) proposed by Holland [1] and Goldberg [2] are inspired by Darwin's theory of biological evolutions. Particle Swarm Optimization (PSO) proposed by Eberhart and Kennedy [3] simulates social behavior of flocks of birds and schools of fishes. Ant Colony Optimization (ACO) formulated by Dorigo [4] imitates foraging behavior of some species of ants. Many other natural-inspired algorithms such as Simulated Annealing (SA) proposed by Kirkpatrick et al. [5], Harmony Search (HS) presented by Geem et al. [6], Gravitational Search Algorithm (GSA) proposed by Rashedi et al. [7], Big Bang-Big Crunch algorithm (BB-BC) proposed by Erol and Eksin [8], and improved by Kaveh and Talathari [9] have been proposed in recent years. Due to their good performance and ease of implementation, these methods have been widely applied to various problems in different fields of science and engineering. Structural optimization is one of the active branches of applications for optimization algorithms $[10-18]$. One of the recently developed meta-heuristic algorithms is the Charged System Search proposed by Kaveh and Talatahari [19] that uses the Coulomb and Gauss laws of physics and Newtonian laws of mechanics to guide some Charged Particles (CPs) to explore search space and locate the optimal solutions. This algorithm is further improved by utilizing the governing laws of magnetic forces and is presented as Magnetic 
Charged System Search by Kaveh et al. [20]. In this algorithm the movements of CPs are determined due to the total force (Lorentz force) instead of using the electric forces merely as in CSS.

In this paper, the MCSS algorithm is applied to some structural optimization problems. The remainder of the paper is organized as follows: in Section 2 a brief review of the MCSS algorithm is presented. In Section 3, the formulation of the structural optimization is presented for truss and frame structures. The MCSS algorithm is then applied to different optimization problems in Section 4. Finally, some concluding remarks are provided in Section 5.

\section{Optimization Algorithm}

Magnetic Charged System Search (MCSS) introduced by Kaveh et al. [20] considers the optimization agents to be moving charged particles exerting a series of electric and magnetic forces on each other. These forces which are determined and controlled on the basis of the solutions' qualities and rates of progress attract the particles gradually to better positions of the search space and lead to eventual convergence.

MCSS assumes the charged particles to be moving through straight virtual wires, as shown in Fig. 11. These wires create a magnetic field on the points surrounding them depending on their radius $(R)$, the electric current passing through them $(I)$, and the distance to the point $(r)$. The other CPs moving in the search space are influenced by these magnetic fields.

The steps of MCSS can be summarized as follows:

\section{Step 1. Initialization}

The initial positions of the CPs are randomly determined using a uniform source, and the initial velocities of the particles are set to zero. A memory is used to save a number of best results. This memory is called the Charged Memory (CM).

Step 2. Determination of electric and magnetic forces and the corresponding movements.

- Electric Force Determination: Each charged particle imposes electric forces on the other CPs according to the magnitude of its charge. The charge of each $\mathrm{CP}$ is:

$$
q_{i}=\frac{f i t(i)-f i t_{\text {worst }}}{\text { fit }_{\text {best }}-f i t_{\text {worst }}}
$$

where $f i t(i)$ is the objective function value of the $i$ th $\mathrm{CP}$, fit $_{\text {best }}$ and fit $_{\text {worst }}$ are the best and worst fitness values so far among all CPs, respectively.

In addition to the electric charge, the magnitudes of the electric forces exerted on the CPs are dependent on the separation distance that is,

$$
r_{i j}=\frac{\left\|\mathbf{X}_{i}-\mathbf{X}_{j}\right\|}{\left\|\left(\mathbf{X}_{i}+\mathbf{X}_{j}\right) / 2-\mathbf{X}_{\text {best }}\right\|+\varepsilon}
$$

where $\mathbf{X}_{i}$ and $\mathbf{X}_{j}$ are the positions of the $i$ th and $j$ th CPs, and $r_{i j}$ is the separation distance of them. $\mathbf{X}_{b e s t}$ is the position of the best current $\mathrm{CP}$, and $\varepsilon$ is a small positive number to prevent singularity.

The probability of the $i$ th $\mathrm{CP}$ being attracted by the $j$ th $\mathrm{CP}$ is expressed as:

$$
p_{i j}=\left\{\begin{array}{l}
1 \Leftrightarrow \frac{f i t(i)-f i t_{\text {best }}}{f i t(j)-f i t(i)}>\text { rand }, \text { or }, \text { fit }(j)>\text { fit }(i) \\
0 \Leftrightarrow \text { else. }
\end{array}\right.
$$

The electric resultant force $\mathbf{F}_{E, j}$, acting on the $j$ th $\mathrm{CP}$ can be calculated by superposing the electric forces exerted by different CPs using the following equation,

$$
\begin{aligned}
& \mathbf{F}_{E, j}=q_{j} \sum_{i, i \neq j}\left(\frac{q_{i}}{R^{3}} r_{i j} \cdot w_{1}+\frac{q_{i}}{r_{i j}^{2}} \cdot w_{2}\right) \cdot p_{j i} \cdot\left(\mathbf{X}_{i}-\mathbf{X}_{j}\right), \\
& \left\{\begin{array}{l}
w_{1}=1, w_{2}=0 \Leftrightarrow r_{i j}<R \\
w_{1}=0, w_{2}=1 \Leftrightarrow r_{i j} \geq R
\end{array}\right. \\
& j=1,2, \ldots, N
\end{aligned}
$$

in which $R$ is the radius of the particles usually taken as unity.

- Magnetic Force Determination: Each CP moves in a virtual wire and produces a magnetic field around itself. The average electric current of the ith $\mathrm{CP}$ in its kth iteration can be calculated as:

$$
\begin{aligned}
& \left(I_{a v g}\right)_{i k}=\operatorname{sign}\left(d f_{i, k}\right) \times \frac{\left|d f_{i, k}\right|-d f_{\text {min }, k}}{d f_{\text {max }, k}-d f_{\text {min }, k}} \\
& d f_{i, k}=f i t_{k}(i)-f i t_{k-1}(i)
\end{aligned}
$$

where $d f_{i, k}$ is the variation of the objective function in the $k$ th movement (iteration). $f i t_{k}(i)$ and $f_{i t_{k-1}}(i)$ are the values of the objective function of the $i$ th CP at the start of the $k$ th and $k-1$ th iterations, respectively.

The value of the magnetic force $\mathbf{F}_{\mathbf{B}, j i}$ exerted on the $j$ th $\mathrm{CP}$ because of the magnetic field produced by the $i$ th virtual wire can be expressed as:

$$
\begin{aligned}
& \mathbf{F}_{\mathbf{B}, j i}=q_{j} \cdot\left(\frac{I_{i}}{R^{2}} r_{i j} \cdot z_{1}+\frac{I_{i}}{r_{i j}} \cdot z_{2}\right) \cdot p m_{j i} \cdot\left(\mathbf{X}_{i}-\mathbf{X}_{j}\right), \\
& \left\{\begin{array}{l}
z_{1}=1, z_{2}=0 \Leftrightarrow r_{i j}<R \\
z_{1}=0, z_{2}=1 \Leftrightarrow r_{i j} \geq R
\end{array}\right.
\end{aligned}
$$

where $q_{i}$ is the charge of the $i$ th $\mathrm{CP}, R$ is the radius of the virtual wires, $I_{i}$ is the average electric current in each wire, and $p m_{j i}$ is the probability of the magnetic influence (attraction or repulsion) of the $i$ th wire on the $j$ th $\mathrm{CP}$. This term can be computed by the following expression:

$$
\operatorname{pm}_{j i}=\left\{\begin{array}{l}
1 \Leftrightarrow \text { fit }(i)>\text { fit }(j) \\
0 \Leftrightarrow \text { else }
\end{array}\right.
$$

This expression indicates that only a good CP can affect a bad $\mathrm{CP}$ by the magnetic force. 


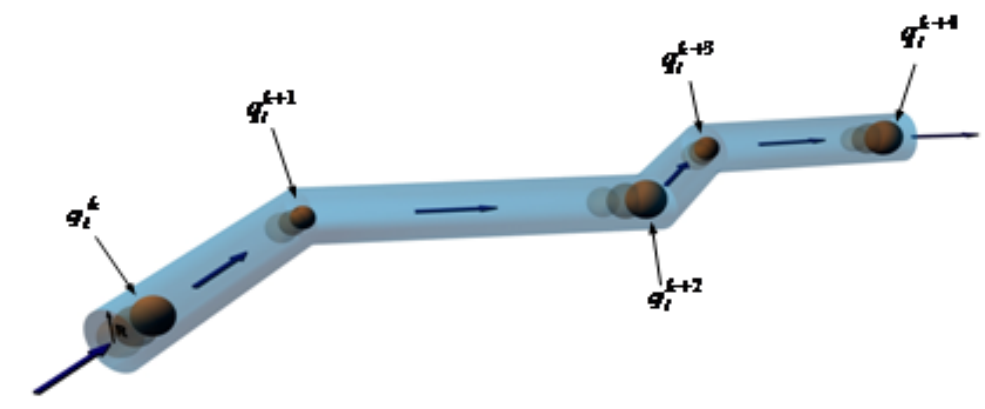

Fig. 1. A schematic view of virtual wire (movement path of a CP), $q_{i}^{k}$ is the charge of $i$ th $\mathrm{CP}$ at the end of the $k$ th iteration (Kaveh et al. [20|).

The resultant magnetic force due to the group of CPs is then calculated as:

$$
\begin{aligned}
& \mathbf{F}_{\mathbf{B}, j}=q_{j} \cdot \sum_{i, i \neq j}\left(\frac{I_{i}}{R^{2}} r_{i j} \cdot z_{1}+\frac{I_{i}}{r_{i j}} \cdot z_{2}\right) \cdot p m_{j i} \cdot\left(\mathbf{X}_{i}-\mathbf{X}_{j}\right), \\
& \left\{\begin{array}{l}
z_{1}=1, z_{2}=0 \Leftrightarrow r_{i j}<R \\
z_{1}=0, z_{2}=1 \Leftrightarrow r_{i j} \geq R \\
j=1,2, \ldots, N
\end{array}\right.
\end{aligned}
$$

- Total Acting Force: the total acting force on the jth CP due to the simultaneous effect of electric and magnetic forces is then evaluated as:

$$
\sum \mathbf{F}_{j}=\mathbf{F}_{B, j}+\mathbf{F}_{E, j}
$$

where $\mathbf{F}_{\mathbf{j}}$ is the total force acting on the $j$ th $\mathrm{CP}$.

- Movement Calculation. Under the influence of the abovementioned forces, each CP moves to its new position:

$$
\begin{aligned}
& \mathbf{X}_{j, \text { new }}=\operatorname{rand}_{j 1} \cdot k_{a} \cdot \frac{\mathbf{F}_{j}}{m_{j}} \cdot \Delta t^{2}+ \\
& + \text { rand }_{j 2} \cdot k_{v} \cdot \mathbf{V}_{j, \text { old }} \cdot \Delta t+\mathbf{X}_{j, \text { old }}, \\
& \mathbf{V}_{j, \text { new }}=\frac{\mathbf{X}_{j, \text { new }}-\mathbf{X}_{j, \text { old }}}{\Delta t}
\end{aligned}
$$

where rand $_{j 1}$ and rand $_{j 2}$ are two random numbers, which are uniformly distributed in the range $(0,1) . k_{a}$ is the acceleration coefficient, $k_{v}$ is the velocity coefficient, and $m_{j}$ is the mass of the particle which is considered to be equal to $q_{j}$. The velocity coefficient controls the influence of the previous velocity of the particles. In other words, this coefficient is related to the exploration ability of the algorithm. The acceleration coefficient controls the effect of the acting force i.e. it influences the exploitation tendency of the algorithm. In order to maintain more exploration at the early iterations and more exploitation at the final iterations the magnitudes of $k_{a}$ and $k_{v}$ are set as:

$$
k_{a}=0.5\left(1+\text { iter } \text { iter }_{\max }\right), \ldots k_{v}=0.5\left(1-\text { iter } / \text { iter }_{\max }\right)
$$

where iter is the current iteration number, and iter $_{\text {max }}$ is the maximum number of iterations. Therefore, the value for $k_{a}$ increases as the optimization process proceeds, while the value for $k_{v}$ decreases.

\section{Step 3. Charged Memory (CM) Updating}

At the end of each iteration the Charged Memory is updated i.e. less good particles stored in previous iterations are discarded and better newly found particles are stored.

Step 4. Checking the Termination Criteria

Steps 2 and 3 are repeated until one of the specified termination criteria is satisfied.

\section{Problem formulation}

\subsection{Truss optimization problem}

In a truss optimization problem the goal is to minimize the weight of the structure while satisfying some constraints. These constraints can be imposed on stresses in members, displacements of nodes, natural frequencies and other response parameters. Cross-sectional areas of the members are considered to be the design variables which can be assumed to change either continuously or discretely. The optimization problem can be stated mathematically as follows:

$$
\begin{aligned}
& \text { Find } X=\left[x_{1}, x_{2}, x_{3}, \ldots, x_{n}\right] \\
& \text { to minimize } \operatorname{Mer}(X)=f(X) \times f_{\text {penalty }}(X)
\end{aligned}
$$

Subject to:

$$
\begin{aligned}
& \sigma_{i \min } \leq \sigma_{i l} \leq \sigma_{i \max } \\
& \delta_{k \min } \leq \delta_{k l} \leq \delta_{k \max } \\
& \omega_{m} \leq \omega_{m}^{*} \text { for some natural frequencies } m \\
& \omega_{n} \geq \omega_{n}^{*} \text { for some natural frequencies } n \\
& i=1,2, \ldots, n m ; k=1,2, \ldots, n n ; l=1,2, \ldots, l c ;
\end{aligned}
$$

where $X$ is the vector containing the design variables; $n m$ and $n n$ are the number of members and nodes of structure, respectively; $l c$ is the number of loading conditions; $n$ is the number of variables which is chosen with respect to symmetry and practice requirements; $\operatorname{Mer}(X)$ is the merit function; $f(X)$ is 
the cost function, which is taken as the weight of the structure; $f_{\text {penalty }}(X)$ is the penalty function which is taken as zero when all of the constraints are satisfied; dc is the number of displacement constraints; $\sigma_{i}$ is the stress of the $i$ th member and $\sigma_{i \text { min }}$ and $\sigma_{i \text { max }}$ are its lower and upper bounds, respectively; $\delta_{j}$ is the displacement of the $j$ th degree of freedom and $\delta_{k \text { min }}$ and $\delta_{k \text { max }}$ are the corresponding lower and upper limits, respectively; $\omega_{m}$ is the $m$ th natural frequency of the structure and $\omega_{m}^{*}$ is its upper bound. $\omega_{n}$ is the $n$th natural frequency of the structure and $\omega_{n}^{*}$ is its lower bound.

The constraints are handled using a penalty function approach. The penalty function can be defined as:

$$
F_{\text {penalty }}(A)=\left(1+\varepsilon_{1} \cdot v\right)^{\varepsilon_{2}}, v=\sum_{i=1}^{q} v_{i}
$$

where $q$ is the number of constraints. If the $i$ th constraint is satisfied $v_{i}$ will be taken as zero, if not it will be taken as:

$$
v_{i}=\left|1-\left(\frac{p_{i}}{p_{i}^{*}}\right)\right|
$$

where $p_{i}$ is the response of the structure and $p_{i}^{*}$ is its bound. The parameters $\varepsilon_{1}$ and $\varepsilon_{2}$ are parameters to the exploration and the exploitation rate of the search process.

\subsection{Frame optimization problem}

Optimal design of frame structures can be mathematically formulated as:

Find $X=\left[x_{1}, x_{2}, x_{3}, \ldots, x_{n}\right]$

to minimizes $\operatorname{Mer}(X)=f(X) \times f_{\text {penalty }}(X)$

subjected to:

$v_{i}^{\sigma}=\left|\frac{\sigma_{i}}{\sigma_{i}^{a}}\right|-1 \geq 0 \quad i=1,2, \ldots, n m$ for stress constraints

$v^{\Delta}=\frac{\Delta}{H}-R \geq 0$ for maximum lateral displacement

$v_{j}^{d}=\frac{d_{j}}{h_{j}}-R j \geq 0 \quad i=1,2, \ldots, n s$

for inter-story drift constraints

Here $\sigma_{I}$ is stress in $i$ th element; $\sigma_{i}^{a}$ is the allowable stress in $i$ th member; $\mathrm{nm}$ is the number of frame members in the structure; $\Delta$ is the maximum lateral displacement; $H$ is the height of the structure; $R$ is the maximum drift index; $d_{j}$ is the inter-story drift; $h_{j}$ is the story height of the $j$ th floor; $n s$ is the total number of stories; and $R_{j}$ is the inter-story drift index permitted by the code of practice.

AISC 2001 [21] is used here for the design of frame structures. The maximum allowable inter-story drift index is taken as 1/300 and for the LRFD interaction formula (AISC 2001, Equa- tion $\mathrm{H} 1-1 \mathrm{a}, \mathrm{b})$, the constrains are defined as:

$$
\begin{aligned}
& v^{I}=\frac{P_{u}}{2 \varphi_{c} P_{n}}+\left(\frac{M_{u x}}{\varphi_{b} M_{n x}}+\frac{M_{u y}}{\varphi_{b} M_{n y}}\right)-1 \geq 0 \\
& \text { for } \frac{P_{u}}{\varphi_{c} P_{n}}<0.2 \\
& v^{I}=\frac{P_{u}}{\varphi_{c} P_{n}}+\frac{8}{9}\left(\frac{M_{u x}}{\varphi_{b} M_{n x}}+\frac{M_{u y}}{\varphi_{b} M_{n y}}\right)-1 \geq 0 \\
& \text { for } \frac{P_{u}}{\varphi_{c} P_{n}} \geq 0.2
\end{aligned}
$$

where $P_{u}$ is the required axial strength (tension or compression); $P_{n}$ is the nominal axial strength (tension or compression); $\varphi_{c}$ is the resistance factor $\left(\varphi_{c}=0.9\right.$ for tension and $\varphi_{c}=0.85$ for compression); $M_{u x}$ and $M_{u y}$ are the required flexural strengths in the $x$ and $y$ directions, respectively; $M_{n x}$ and $M_{n y}$ are the nominal flexural strengths in the $x$ and $y$ directions (for two-dimensional structures, $\left.M_{n y}=0\right)$; and $\varphi_{b}$ is the flexural resistance reduction factor $\left(\varphi_{b}=0.9\right)$.

The same penalty function as used in truss optimization can be used here.

\section{Numerical Examples}

Four numerical examples consisting of both frames and trusses with different performance constraints are considered here:

- A ten-bar truss with frequency constraints

- A 72-bar spatial truss with stress and displacement constraints

- A one-bay eight-story frame with lateral drift constraint

- A three-bay 24-story frame with LRFD specification and inter-story drift constraints

A population of $25 \mathrm{CPs}$ is considered for the first three examples and $50 \mathrm{CPs}$ are used for the last one. Maximum number of iterations is considered as the termination criterion. The optimal results obtained from the proposed algorithm are compared to some of the previously reported results. These comparisons indicate the viability of the algorithm in solving different types of structural optimization problems.

In order to calculate the effective length factors which are needed in example 4 the following approximate formula based on Dumonteil [22] is used:

$$
K=\sqrt{\frac{1.6 G_{A} G_{B}+4\left(G_{A}+G_{B}\right)+7.5}{G_{A}+G_{B}+7.5}}
$$

where $G_{A}$ and $G_{B}$ refer to the stiffness ratio or the relative stiffness of a column at its two ends.

\section{Example 1: A ten-bar truss}

Frequency constraint size optimization of a 10-bar planar truss as shown in Fig. 2 is considered as the first example. 
This example is viewed as one of the most well-known benchmark problems in frequency constraint structural optimization. Each member's cross-sectional area is regarded as an independent continuous variable. A non-structural mass of $454.0 \mathrm{~kg}$ is attached to the free nodes. Table 1 shows the material properties, variable bounds, and frequency constraints for this example. This problem has been investigated by Grandhi and Venkayya [23] using the optimality algorithm. Sedaghati, et al. [24] have solved it by sequential quadratic programming and the finite element force method. Wang et al. [25] have used an evolutionary node shift method and Lingyun et al. [26] have used a niche hybrid genetic algorithm to optimize this structure. Gomes [27] has analyzed this problem using the particle swarm algorithm. Kaveh and Zolghadr have investigated the problem using the standard and an enhanced CSS [28] and a hybridized CSS-BBBC algorithm with trap recognition capability [29].

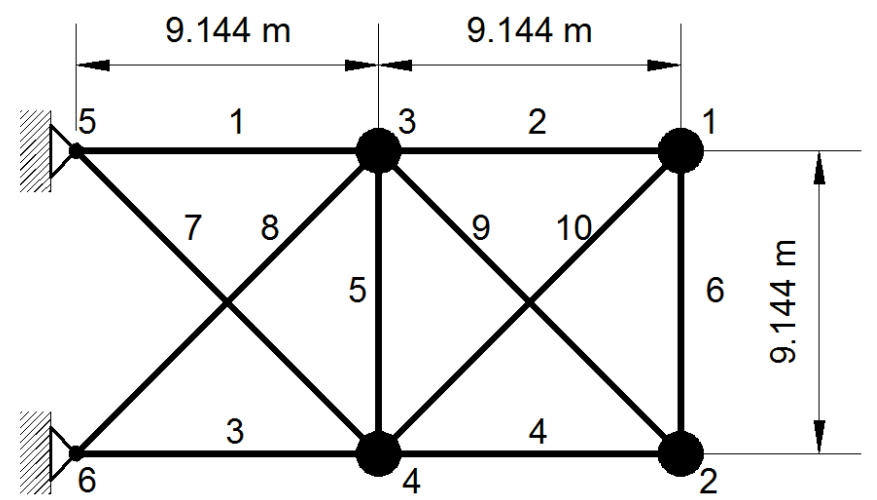

Fig. 2. A ten-bar planar truss with masses shown in bigger solid circles

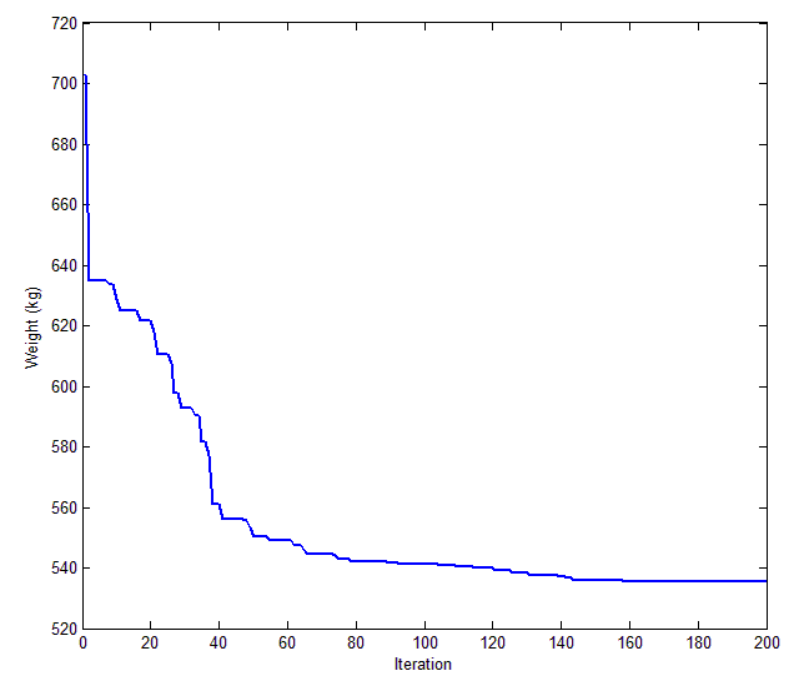

Fig. 3. Convergence curve of the best run for the 10-bar planar truss

Table 2 shows the optimal solutions found by different algorithms. It should be noted that a modulus of elasticity of $E=6.98 \times 10^{10} \mathrm{~Pa}$ is used in Gomes [27] and Kaveh and Zolghadr [23,24]. This will generally result in relatively lighter structures. Considering this, it appears that the proposed algorithm has obtained one of the best solutions so far. Using $E=6.98 \times 10^{10} \mathrm{~Pa}$ the proposd algorithm finds a structure weighted $529.11 \mathrm{~kg}$, which is lighter than that of CSS and enhanced CSS and is only slightly heavier than CSS-BBBC.

Table 3 presents the natural frequencies of the optimized structures obtained by different methods. All of the constraints are satisfied according to the table with an exception of the structure found by Sedaghati et al. [24]

The convergence curve of the best run of the MCSS optimizing the 10-bar planar truss is depicted in Fig. 3 .

\section{Example 2: A 72-bar spatial truss}

A 72-bar space truss as shown in Fig. 4 is considered as the second example. This problem has been studied previously by $\mathrm{Wu}$ and Chow [30], Li et al [31] and Kaveh and Talatahari [32] among others. The material density is $0.1 \mathrm{lb} / \mathrm{in}^{3}$ $\left(2767.990 \mathrm{~kg} / \mathrm{m}^{3}\right)$ and the modulus of elasticity is $10,000 \mathrm{ksi}$ $(68,950 \mathrm{MPa})$. The members are subjected to stress limitations of $\pm 25 \mathrm{ksi}( \pm 172.375 \mathrm{MPa})$. The uppermost nodes are subjected to displacement limitations of \pm 0.25 in $( \pm 0.635 \mathrm{~cm})$ both in $x$ and $y$ directions. The discrete variables are selected from Table 4 The loading conditions applied to the structure are listed in Table 5. The elements of this structure are grouped in 16 groups according to Table 6 .

Optimal results obtained by different methods are listed in Table 7. It can be seen that the MCSS algorithm has obtained the best results. Fig. 5 represents the convergence curve of the best run of MCSS for the 72-bar spatial truss.

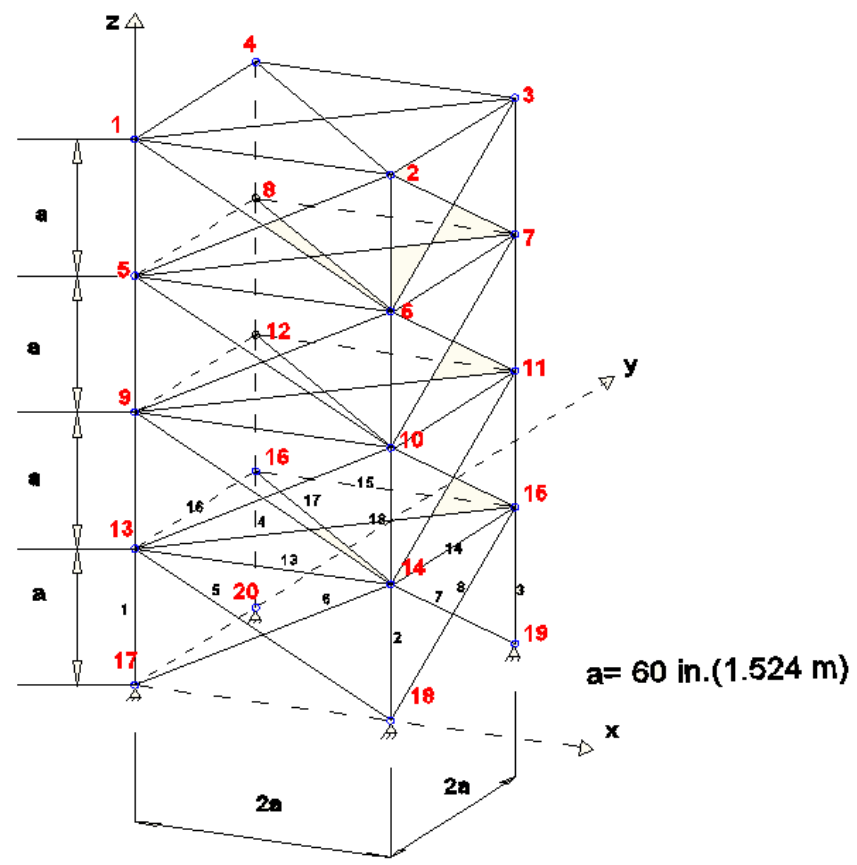

Fig. 4. Node and element numbering scheme for the 72-bar spatial truss 
Tab. 1. Material properties, variable bounds and frequency constraints for the 10-bar truss structure

\begin{tabular}{cc}
\hline Property/unite & Value \\
\hline$E$ (Modulus of elasticity) $/ \mathrm{N} / \mathrm{m}^{2}$ & $6.89 \times 10^{10}$ \\
\hline$\rho$ (Material density) $/ \mathrm{kg} / \mathrm{m}^{3}$ & 2770.0 \\
\hline Added mass $/ \mathrm{kg}$ & 454.0 \\
\hline Design variable lower bound $/ \mathrm{m}^{2}$ & $0.645 \times 10^{-4}$ \\
\hline $\mathrm{L}$ (Main bar's dimension) $/ \mathrm{m}$ & 9.144 \\
\hline Constraints on first three frequencies $/ \mathrm{Hz}$ & $\omega_{1} \geq 7, \omega_{2} \geq 15, \omega_{3} \geq 20$ \\
\hline
\end{tabular}

Tab. 2. Optimal design cross sections $\left(\mathrm{cm}^{2}\right)$ for several methods for the ten bar planar truss (weight does not include added masses).

\begin{tabular}{|c|c|c|c|c|c|c|c|c|c|}
\hline \multirow{2}{*}{$\begin{array}{l}\text { Element } \\
\text { number }\end{array}$} & \multirow{2}{*}{$\begin{array}{c}\text { Grandhi } \\
\text { and } \\
\text { Venkayya } \\
23\end{array}$} & \multirow{2}{*}{$\begin{array}{l}\text { Sedaghati } \\
\text { et al. } \\
24 .\end{array}$} & \multirow{2}{*}{$\begin{array}{c}\text { Wang } \\
\text { et al. } \\
25\end{array}$} & \multirow{2}{*}{$\begin{array}{l}\text { Lingyun } \\
\text { et al. } \\
26 .\end{array}$} & \multirow{2}{*}{$\begin{array}{c}\text { Gomes } \\
27\end{array}$} & \multicolumn{3}{|c|}{ Kaveh and Zolghadr } & \multirow[b]{2}{*}{$\begin{array}{c}\text { Present } \\
\text { work }\end{array}$} \\
\hline & & & & & & $\begin{array}{c}\text { Standard } \\
\text { CSS } \\
28\end{array}$ & $\begin{array}{c}\text { Enhanced } \\
\text { cSS } \\
28\end{array}$ & $\begin{array}{c}\text { CSS- } \\
\text { BBBC } \\
29\end{array}$ & \\
\hline 1 & 36.584 & 38.245 & 32.456 & 42.23 & 37.712 & 38.811 & 39.569 & 35.274 & 37.727 \\
\hline 2 & 24.658 & 9.916 & 16.577 & 18.555 & 9.959 & 9.0307 & 16.740 & 15.463 & 14.216 \\
\hline 3 & 36.584 & 38.619 & 32.456 & 38.851 & 40.265 & 37.099 & 34.361 & 32.11 & 35.206 \\
\hline 4 & 24.658 & 18.232 & 16.577 & 11.222 & 16.788 & 18.479 & 12.994 & 14.065 & 16.413 \\
\hline 5 & 4.167 & 4.419 & 2.115 & 4.783 & 11.576 & 4.479 & 0.645 & 0.645 & 0.657 \\
\hline 6 & 2.070 & 4.419 & 4.467 & 4.451 & 3.955 & 4.205 & 4.802 & 4.880 & 4.639 \\
\hline 7 & 27.032 & 20.097 & 22.810 & 21.049 & 25.308 & 20.842 & 26.182 & 24.046 & 22.246 \\
\hline 8 & 27.032 & 24.097 & 22.810 & 20.949 & 21.613 & 23.023 & 21.260 & 24.340 & 25.447 \\
\hline 9 & 10.346 & 13.890 & 17.490 & 10.257 & 11.576 & 13.763 & 11.766 & 13.343 & 10.822 \\
\hline 10 & 10.346 & 11.452 & 17.490 & 14.342 & 11.186 & 11.414 & 11.392 & 13.543 & 13.953 \\
\hline $\begin{array}{c}\text { Weight } \\
(\mathrm{kg})\end{array}$ & 594.0 & 537.01 & 553.8 & 542.75 & 537.98 & 531.95 & 529.25 & 529.09 & 535.31 \\
\hline
\end{tabular}

Tab. 3. Natural frequencies $(\mathrm{Hz})$ of the optimized structures (the ten-bar planar truss)

\begin{tabular}{|c|c|c|c|c|c|c|c|c|c|}
\hline \multicolumn{2}{|c|}{ Frequency Grandhi } & \multirow{2}{*}{$\begin{array}{l}\text { Sedaghati } \\
\text { et al. } \\
24 .\end{array}$} & \multirow{2}{*}{$\begin{array}{l}\text { Wang } \\
\text { et al. } \\
25\end{array}$} & \multirow{2}{*}{$\begin{array}{l}\text { Lingyun } \\
\text { et al. } \\
26 .\end{array}$} & \multirow{2}{*}{$\begin{array}{c}\text { Gomes } \\
27\end{array}$} & \multicolumn{3}{|c|}{ Kaveh and Zolghadr } & \multirow[b]{2}{*}{$\begin{array}{c}\text { Present } \\
\text { work }\end{array}$} \\
\hline number & $\begin{array}{c}\text { and } \\
\text { Venkayya } \\
23\end{array}$ & & & & & $\begin{array}{c}\text { Standard } \\
\text { CSS } \\
28\end{array}$ & $\begin{array}{c}\text { Enhanced } \\
\text { CSS } \\
28\end{array}$ & $\begin{array}{c}\text { CSS- } \\
\text { BBBC } \\
29\end{array}$ & \\
\hline 1 & 7.059 & 6.992 & 7.011 & 7.008 & 7.000 & 7.000 & 7.000 & 7.000 & 7.000 \\
\hline 2 & 15.895 & 17.599 & 17.302 & 18.148 & 17.786 & 17.442 & 16.238 & 16.119 & 16.244 \\
\hline 3 & 20.425 & 19.973 & 20.001 & 20.000 & 20.000 & 20.031 & 20.000 & 20.075 & 20.002 \\
\hline 4 & 21.528 & 19.977 & 20.100 & 20.508 & 20.063 & 20.208 & 20.361 & 20.457 & 20.066 \\
\hline 5 & 28.978 & 28. 173 & 30.869 & 27.797 & 27.776 & 28.261 & 28.121 & 29.149 & 27.796 \\
\hline 6 & 30.189 & 31.029 & 32.666 & 31.281 & 30.939 & 31.139 & 28.610 & 29.761 & 29.520 \\
\hline 7 & 54.286 & 47.628 & 48.282 & 48.304 & 47.297 & 47.704 & 48.390 & 47.950 & 48.994 \\
\hline 8 & 56.546 & 52.292 & 52.306 & 53.306 & 52.286 & 52.420 & 52.291 & 51.215 & 51.492 \\
\hline
\end{tabular}


Tab. 4. The available cross-sectional areas of the ASIC 1989 code [33].

\begin{tabular}{|c|c|c|c|c|c|}
\hline No. & in $^{2}$ & $\mathrm{~mm}^{2}$ & No. & in $^{2}$ & $\mathrm{~mm}^{2}$ \\
\hline 1 & 0.111 & 71.613 & 33 & 3.840 & 2477.423 \\
\hline 2 & 0.141 & 90.96786 & 34 & 3.870 & 2496.778 \\
\hline 3 & 0.196 & 126.4518 & 35 & 3.880 & 2503.229 \\
\hline 4 & 0.250 & 161.2905 & 36 & 4.180 & 2696.778 \\
\hline 5 & 0.307 & 198.0648 & 37 & 4.220 & 2722.584 \\
\hline 6 & 0.391 & 252.2584 & 38 & 4.490 & 2896.778 \\
\hline 7 & 0.442 & 285.1617 & 39 & 4.590 & 2961.294 \\
\hline 8 & 0.563 & 363.2263 & 40 & 4.800 & 3096.778 \\
\hline 9 & 0.602 & 388.3876 & 41 & 4.970 & 3206.456 \\
\hline 10 & 0.766 & 494.1942 & 42 & 5.120 & 3303.23 \\
\hline 11 & 0.785 & 506.4523 & 43 & 5.740 & 3703.231 \\
\hline 12 & 0.994 & 641.2912 & 44 & 7.220 & 4658.071 \\
\hline 13 & 1.000 & 645.1622 & 45 & 7.970 & 5141.942 \\
\hline 14 & 1.228 & 792.2591 & 46 & 8.530 & 5503.233 \\
\hline 15 & 1.266 & 816.7753 & 47 & 9.300 & 6000.008 \\
\hline 16 & 1.457 & 940.0013 & 48 & 10.850 & 7000.009 \\
\hline 17 & 1.563 & 1008.388 & 49 & 11.500 & 7419.365 \\
\hline 18 & 1.620 & 1045.163 & 50 & 13.500 & 8709.689 \\
\hline 19 & 1.800 & 1161.292 & 51 & 13.900 & 8967.754 \\
\hline 20 & 1.990 & 1283.873 & 52 & 14.200 & 9161.303 \\
\hline 21 & 2.130 & 1374.195 & 53 & 15.500 & 10000.01 \\
\hline 22 & 2.380 & 1535.486 & 54 & 16.000 & 10322.59 \\
\hline 23 & 2.620 & 1690.325 & 55 & 16.900 & 10903.24 \\
\hline 24 & 2.630 & 1696.776 & 56 & 18.800 & 12129.05 \\
\hline 25 & 2.880 & 1858.067 & 57 & 19.900 & 12838.73 \\
\hline 26 & 2.930 & 1890.325 & 58 & 22.000 & 14193.57 \\
\hline 27 & 3.090 & 1993.551 & 59 & 22.900 & 14774.21 \\
\hline 28 & 1.130 & 729.0332 & 60 & 24.500 & 15806.47 \\
\hline 29 & 3.380 & 2180.648 & 61 & 26.500 & 17096.8 \\
\hline 30 & 3.470 & 2238.713 & 62 & 28.000 & 18064.54 \\
\hline 31 & 3.550 & 2290.326 & 63 & 30.000 & 19354.86 \\
\hline 32 & 3.630 & 2341.939 & 64 & 33.500 & 21612.93 \\
\hline
\end{tabular}

Tab. 5. Loading conditions for the 72-bar space truss.

\begin{tabular}{ccccccc}
\hline node & \multicolumn{3}{c}{ Case 1 } & & \multicolumn{3}{c}{ Case 2 } \\
\hline & Px kips $(\mathrm{kN})$ & Py kips $(\mathrm{kN})$ & Pz kips $(\mathrm{kN})$ & Px kips $(\mathrm{kN})$ & Py kips $(\mathrm{kN})$ & Pz kips $(\mathrm{kN})$ \\
\hline 1 & $0.5(-22.25)$ & $0.5(22.25)$ & $-0.5(-22.25)$ & - & - & $-0.5(-22.25)$ \\
\hline 2 & - & - & - & - & - & $-0.5(-22.25)$ \\
\hline 3 & - & - & - & - & - & $-0.5(-22.25)$ \\
\hline 4 & - & - & - & - & - & $-0.5(-22.25)$ \\
\hline
\end{tabular}


Tab. 6. Element grouping for the 72-bar truss.

\begin{tabular}{cccc}
\hline Group number & Elements & Group number & Elements \\
\hline 1 & A1-A4 & 9 & A37-A40 \\
\hline 2 & A5-A12 & 10 & A41-A48 \\
\hline 3 & A13-A16 & 11 & A49-A52 \\
\hline 4 & A17-A18 & 12 & A53-A54 \\
\hline 5 & A19-A22 & 13 & A55-A58 \\
\hline 6 & A23-A30 & 14 & A59-A66 \\
\hline 7 & A31-A34 & 15 & A67-A70 \\
\hline 8 & A35-A36 & 16 & A71-A72
\end{tabular}

Tab. 7. Comparison of optimal designs for the 72-bar spatial truss structure

\begin{tabular}{|c|c|c|c|c|c|}
\hline \multirow[t]{2}{*}{ Variables (in ${ }^{2}$ ) } & \multirow{2}{*}{$\begin{array}{c}\text { Wu and Chow } \\
30\end{array}$} & \multirow[t]{2}{*}{ Li et al. 31} & \multirow{2}{*}{$\begin{array}{c}\text { Kaveh and } \\
\text { Talatahari } 32\end{array}$} & \multicolumn{2}{|c|}{ Present work in ${ }^{2}\left(\mathrm{~cm}^{2}\right)$} \\
\hline & & & & CSS & MCSS \\
\hline 1 & 0.196 & 4.97 & 1.800 & $0.141(0.91)$ & $0.141(0.91)$ \\
\hline 2 & 0.602 & 1.228 & 0.442 & $0.391(2.52)$ & $0.391(2.52)$ \\
\hline 3 & 0.307 & 0.111 & 0.141 & $0.196(1.26)$ & $0.196(1.26)$ \\
\hline 4 & 0.766 & 0.111 & 0.111 & $0.563(3.63)$ & $0.442(2.85)$ \\
\hline 5 & 0.391 & 2.880 & 1.228 & $0.250(1.61)$ & $0.307(1.98)$ \\
\hline 6 & 0.391 & 1.457 & 0.563 & $0.307(1.98)$ & $0.307(1.98)$ \\
\hline 7 & 0.141 & 0.141 & 0.111 & $0.111(0.72)$ & $0.111(0.72)$ \\
\hline 8 & 0.111 & 0.111 & 0.111 & $0.111(0.72)$ & $0.111(0.72)$ \\
\hline 9 & 1.800 & 1.563 & 0.563 & $1.228(7.92)$ & $1.266(8.17)$ \\
\hline 10 & 0.602 & 1.228 & 0.563 & $0.391(2.52)$ & $0.307(1.98)$ \\
\hline 11 & 0.141 & 0.111 & 0.111 & $0.111(0.72)$ & $0.111(0.72)$ \\
\hline 12 & 0.307 & 0.196 & 0.250 & $0.111(0.72)$ & $0.111(0.72)$ \\
\hline 13 & 1.563 & 0.391 & 0.196 & $1.563(10.08)$ & $1.99(12.84)$ \\
\hline 14 & 0.766 & 1.457 & 0.563 & 0.307 (1.98) & 0.307 (1.98) \\
\hline 15 & 0.141 & 0.766 & 0.442 & $0.111(0.72)$ & $0.111(0.72)$ \\
\hline 16 & 0.111 & 1.563 & 0.563 & $0.111(0.72)$ & $0.111(0.72)$ \\
\hline Weight (lb) & 427.203 & 933.09 & 393.380 & $\begin{array}{c}391.063 \\
(176.95 \mathrm{~kg})\end{array}$ & $\begin{array}{c}388.936 \\
(175.99 \mathrm{~kg})\end{array}$ \\
\hline
\end{tabular}




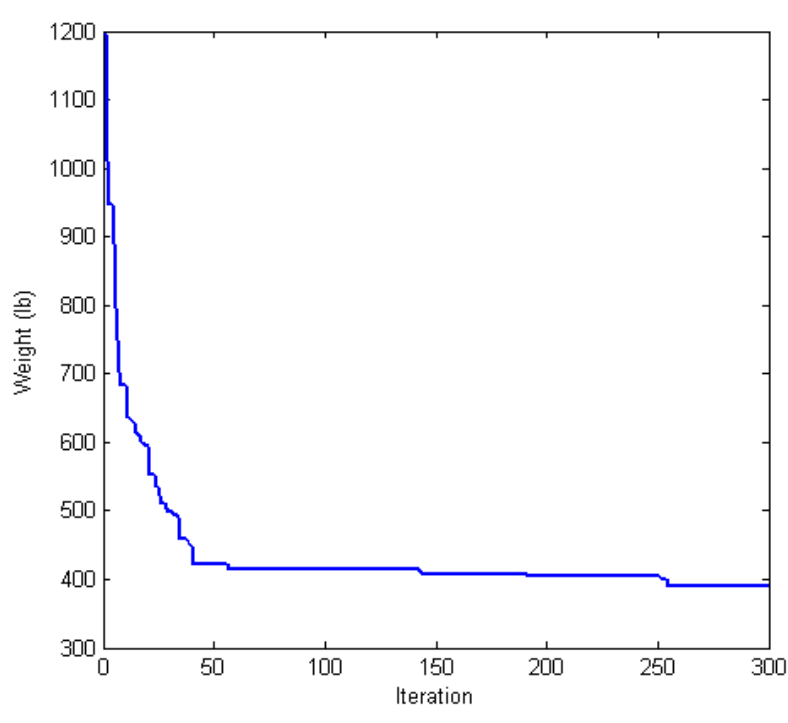

Fig. 5. Convergence curve of the best run for the 72-bar spatial truss

According to Table 7, MCSS obtains the lightest structure among the present methods. For further comparison, the problem is also solved using the standard CSS. It can be seen that the MCSS performs slightly better than the standard CSS.

Example 3: A one-bay eight-story frame

Configuration and the applied loads of a one-bay eight-story frame are depicted in Fig. 6. Several researchers have optimized this structure using different optimization approaches. Khot et al. [34] used an optimality criterion to investigate it. Camp et al. [35] optimized it using a Genetic algorithm and Kaveh and Shojaee [36] and Kaveh and Talatahari [37] utilized ACO and IACO to solve it.

The 24 elements of the structure are grouped into 8 design variables; the same beam section to be used for two consecutive stories, beginning at the foundation, and that the same column section is used every two consecutive stories. The only performance constraint is considered to be the structure's lateral drift at the top story (no more than $5.08 \mathrm{~cm}$ ). The modulus of elasticity of the material used is taken as $E=200 \mathrm{GPa}$. All frame sections are chosen from the entire set of $267 \mathrm{~W}$-shapes.

Table 8 presents a comparison between the best results obtained by different methods for the one-bay eight-story frame. Fig. 7 shows the convergence curve of the best run for the onebay eight-story frame.

Table 8 indicates that the present algorithm has obtained the best result for this example. Comparison of the results shows that the performance of MCSS is better than that of CSS.

\section{Example 4: A 3-bay 24-story frame}

Topology and applied loads of a 3-bay 24-story frame are depicted in Fig. 8. This structure has been designed originally by Davison and Adams [38]. Saka and Kameshki [39] utilized a GA algorithm to obtain a least-weight design conforming to AISC specifications [23] and to BS 5950 [40]. Camp et al. [41] utilized ACO conforming to AISC specifications [23]. Kaveh

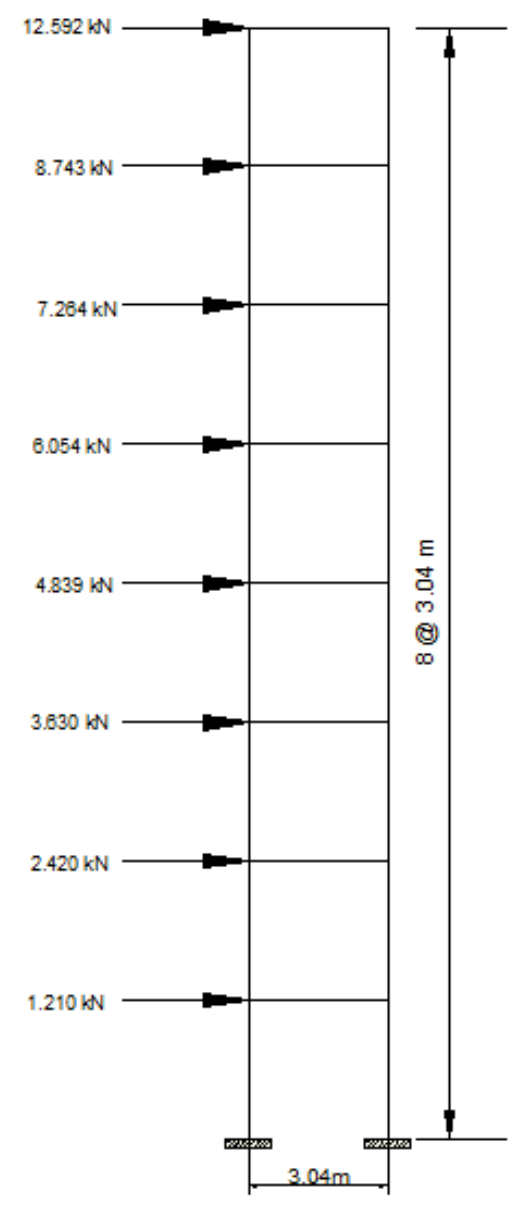

Fig. 6. A one-bay eight-story frame

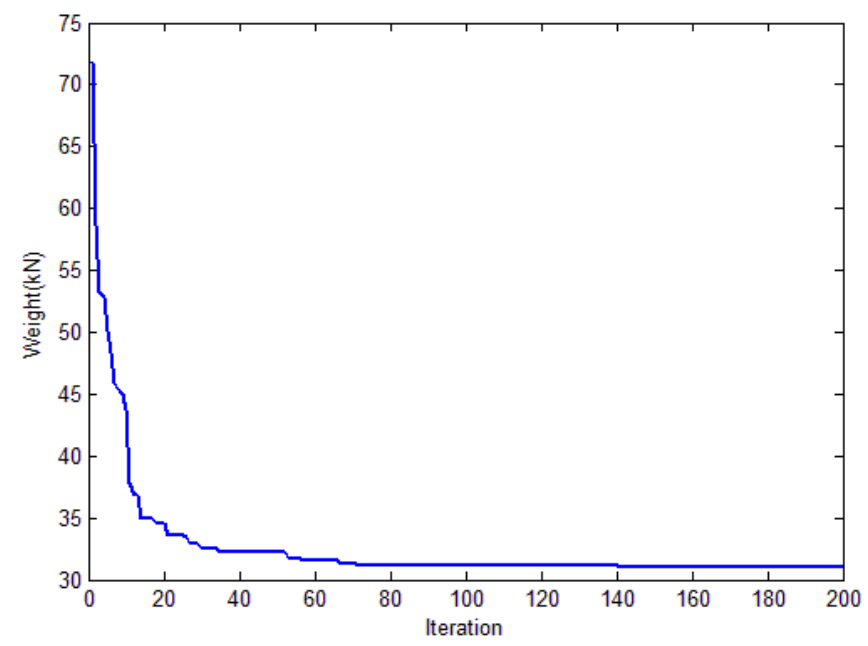

Fig. 7. Convergence curve of the best run for the one-bay eight-story frame

and Talatahari [37] used an improved ACO to develop a design conforming to the LRFD specification (AISC 2001) and used an inter-story drift displacement constraint. Kaveh and Talatahari [42] utilized standard CSS to optimize the structure using the same constraints. Here LRFD interaction formula (AISC 2001) together with inter-story drift is considered as performance constraints. The modulus of elasticity of the material is taken as $E=205 \mathrm{GPa}$ and it's yield stress as $f_{y}=230.3 \mathrm{MPa}$. 
Tab. 8. Comparison of the best results for the one-bay eight-story frame

\begin{tabular}{|c|c|c|c|c|c|c|c|}
\hline \multirow{3}{*}{$\begin{array}{l}\text { Element } \\
\text { group no. }\end{array}$} & \multicolumn{7}{|c|}{ AISC W-shapes } \\
\hline & \multirow[t]{2}{*}{$\begin{array}{c}\text { Element } \\
\text { group }\end{array}$} & \multirow{2}{*}{$\begin{array}{c}\text { Khot et al. } \\
34\end{array}$} & \multirow[t]{2}{*}{$\begin{array}{l}\text { Camp et } \\
\text { al. } 35\end{array}$} & \multirow{2}{*}{$\begin{array}{c}\text { Kaveh } \\
\text { and } \\
\text { Shojaee } \\
36\end{array}$} & \multirow{2}{*}{$\begin{array}{c}\begin{array}{c}\text { Kaveh } \\
\text { and } \\
\text { Talatahari } \\
37\end{array} \\
\text { 3. }\end{array}$} & \multicolumn{2}{|c|}{ Proposed algorithm } \\
\hline & & & & & & CSS & MCSS \\
\hline 1 & $\begin{array}{c}\text { Beam } \\
1-2 S\end{array}$ & W21X68 & W18X35 & W16X26 & W21X44 & W21X44 & W16X31 \\
\hline 2 & $\begin{array}{l}\text { Beam } \\
3-4 S\end{array}$ & W24X55 & W18X35 & W18X40 & W18X35 & W16X31 & W18X35 \\
\hline 3 & $\begin{array}{c}\text { Beam } \\
5-6 S\end{array}$ & W21X50 & W18X35 & W18X35 & W18X35 & W16X26 & W16X26 \\
\hline 4 & $\begin{array}{c}\text { Beam } \\
7-8 S\end{array}$ & W12X40 & W18X26 & W12X22 & W12X22 & W16X26 & W16X26 \\
\hline 5 & $\begin{array}{c}\text { Column } \\
1-2 S\end{array}$ & W14X34 & W18X46 & W18X40 & W18X40 & W18X40 & W21X44 \\
\hline 6 & $\begin{array}{c}\text { Column } \\
3-4 S\end{array}$ & W10X 39 & W16X31 & W16X26 & W16X26 & W14X30 & W18X35 \\
\hline 7 & $\begin{array}{c}\text { Column } \\
5-6 S\end{array}$ & W10X 33 & W16X26 & W16X26 & W16X26 & W16X26 & W14X22 \\
\hline 8 & $\begin{array}{c}\text { Column } \\
7-8 S\end{array}$ & W8X 18 & W12X16 & W12X14 & W12X14 & W12X19 & W12X14 \\
\hline $\begin{array}{c}\text { Weight } \\
(\mathrm{kN})\end{array}$ & & 41.02 & 32.83 & 31.68 & 31.05 & 31.73 & 30.98 \\
\hline
\end{tabular}

The structure's 168 elements are grouped as follows: the same beam section is used in the first and third bay on all floors except for the roof, the beams of the second bay share the same section on all floors except for the roof, the first and third bay beams on the roof share the same section, the beam of the second bay on the roof is an independent variable. This results in 4 beam groups. The exterior columns are combined into one group and the interior columns are combined into another group over three consecutive stories beginning from the foundation. This results in 16 column section groups.

The effective length factor of the members are calculated as $K_{x} \geq 1$ for a sway-permitted frame and the out-of-plan effective length factors are considered as $K_{y}=1$. All of the members are assumed to be unbraced along their lengths.

Two different optimization cases are considered here. In Case 1 the beam sections can be selected from the entire list of $\mathrm{W}$ shapes while the columns are restricted to W14 sections. In Case 2 all the elements are free to be chosen from the entire list of $\mathrm{W}$ shapes.

According to Table 9, the present algorithm finds the best results in both cases. It is also seen that the MCSS performs better than the standard CSS for the cases considered in Kaveh and Talatahari [42].

Fig. 9 and Fig. 10 show the convergence curves of the best runs of MCSS for the 3-bay 24-story frame structure in Case 1 and Case 2, respectively. Fig. 11 and Fig. 12 represent the stress ratios for the members of the 3-bay 24-story frame in Case 1 and
Case 2, respectively. Fig. 13 depicts the inter-story drift of the optimal structures in Cases 1 and 2.

\section{Concluding remarks}

A newly proposed meta-heuristic algorithm named Magnetic Charged System Search Kaveh et al. [20], which can be considered as an extension of the standard CSS proposed by Kaveh and Talatahari [19], is utilized here for optimal design of truss and frame structures.

MCSS maintains some extra information about the search space by introducing additional forces called magnetic forces into the standard CSS. These forces are supposed to portray the improvements of the objective function values of the CPs ignoring their relative excellence among the population.

The MCSS algorithm is applied to four structural examples including trusses and frames with different performance constraints. Comparisons of the obtained results with those available in the literature indicate the superiority of the algorithm in finding optimal solutions in the studied examples. Comparisons show that the MCSS generally performances better than the standard CSS.

\section{Acknowledgement}

The first author is grateful to the Iran National Science Foundation for the support. 
Tab. 9. Comparison of the optimal structures attained by different researchers for the 3-bay 24-story frame.

\begin{tabular}{|c|c|c|c|c|c|c|c|c|c|}
\hline \multirow{3}{*}{$\begin{array}{c}\text { Element } \\
\text { group no. }\end{array}$} & \multicolumn{9}{|c|}{ AISC W-shapes } \\
\hline & \multirow{2}{*}{$\begin{array}{c}\text { Element } \\
\text { group }\end{array}$} & \multirow[t]{2}{*}{ Saka and Kameshki 39} & \multirow{2}{*}{$\begin{array}{c}\text { Camp et } \\
\text { al. } 41\end{array}$} & \multirow{2}{*}{$\begin{array}{c}\text { Degertekin } \\
443 .\end{array}$} & \multicolumn{2}{|c|}{ Kaveh and Talatahari 37. } & \multirow{2}{*}{$\frac{42}{\text { Case } 1}$} & \multicolumn{2}{|c|}{ Present algorithm } \\
\hline & & & & & Case 1 & Case 2 & & Case 1 & Case 2 \\
\hline 1 & $\begin{array}{c}\text { Beam } \\
\text { 1-23S, } \\
\text { Bay 1,3 }\end{array}$ & $838 X 292 X 194 U B$ & W30X90 & W30X90 & W30X99 & W30X99 & W30X90 & W27X84 & W30X90 \\
\hline 2 & $\begin{array}{c}\text { Beam } \\
24 S, \text { Bay } \\
1,3\end{array}$ & $305 \times 102 X 25 U B$ & W8X18 & W10X22 & W16X26 & W10X33 & W21X50 & W14X22 & W14X22 \\
\hline 3 & $\begin{array}{c}\text { Beam } \\
\text { 1-23S, } \\
\text { Bay } 2\end{array}$ & $457 X 191 X 82 U B$ & W24X55 & W18X40 & W18X35 & W18X35 & W21X48 & W21X48 & W18X35 \\
\hline 4 & $\begin{array}{c}\text { Beam } \\
\text { 24S, Bay } \\
2\end{array}$ & $305 \times 102 X 25 U B$ & W8X21 & W12X16 & W14X22 & W16X31 & W12X19 & W14X22 & W14X22 \\
\hline 5 & $\begin{array}{l}\text { Column } \\
1-3 S, E\end{array}$ & $305 \times 102 \times 25 U C$ & W14X145 & W14X176 & W14X145 & W36X170 & W14X176 & W14X145 & W27X102 \\
\hline 6 & $\begin{array}{l}\text { Column } \\
4-6 S, E\end{array}$ & $305 \times 368 \times 129 \cup C$ & W14X132 & W14X176 & W14X132 & W30X116 & W14X145 & W14X176 & W30X132 \\
\hline 7 & $\begin{array}{l}\text { Column } \\
\text { 7-9S, E }\end{array}$ & $305 \times 305 \times 97 \cup C$ & W14X132 & W14X132 & W14X120 & W30X116 & W14X109 & W14X109 & W30X108 \\
\hline 8 & $\begin{array}{c}\text { Column } \\
\text { 10-12S, E }\end{array}$ & $356 \times 368 \times 129 \cup C$ & W14X132 & W14X109 & W14X109 & W24X62 & W14X90 & W14X109 & W27X84 \\
\hline 9 & $\begin{array}{c}\text { Column } \\
\text { 13-15S, E }\end{array}$ & $305 \times 305 X 97 \cup C$ & W14X68 & W14X82 & W14X48 & W24X62 & W14X74 & W14X90 & W14X43 \\
\hline 10 & $\begin{array}{c}\text { Column } \\
\text { 16-18S, E }\end{array}$ & $203 \times 203 \times 71 U C$ & W14X53 & W14X74 & W14X48 & W18X60 & W14X61 & W14X43 & W18X71 \\
\hline 11 & $\begin{array}{c}\text { Column } \\
\text { 19-21S, E }\end{array}$ & $305 \times 305 \times 118 U C$ & W14X43 & W14X34 & W14X34 & W16X36 & W14X34 & W14X43 & W24X55 \\
\hline 12 & $\begin{array}{c}\text { Column } \\
21-24 S, E\end{array}$ & 152X152X23UC & W14X43 & W14X22 & W14X30 & W10X33 & W14X34 & W14X22 & W30X90 \\
\hline 13 & $\begin{array}{c}\text { Column } \\
\text { 1-3S, I }\end{array}$ & $305 \times 305 \times 137 \cup C$ & W14X145 & W14X145 & W14X159 & W24X76 & W14X145 & W14X145 & W24X68 \\
\hline 14 & $\begin{array}{c}\text { Column } \\
4-6 S, I\end{array}$ & $305 \times 305 \times 198 \cup C$ & W14X145 & W14X132 & W14X120 & W14X74 & W14X132 & W14X120 & W21X62 \\
\hline 15 & $\begin{array}{c}\text { Column } \\
7-9 \mathrm{~S}, \mathrm{I}\end{array}$ & $356 \times 368 \times 202 U C$ & W14X120 & W14X109 & W14X109 & W24X62 & W14X109 & W14X132 & W14X90 \\
\hline 16 & $\begin{array}{c}\text { Column } \\
10-12 S, I \\
\end{array}$ & $356 \times 368 \times 129 \cup C$ & W14X90 & W14X82 & W14X99 & W24X62 & W14X82 & W14X90 & W16X67 \\
\hline 17 & $\begin{array}{c}\text { Column } \\
13-15 \mathrm{~S}, \mathrm{I}\end{array}$ & $356 \times 368 \times 129 \cup C$ & W14X90 & W14X61 & W14X82 & W18X46 & W14X68 & W14X68 & W27X114 \\
\hline 18 & $\begin{array}{l}\text { Column } \\
16-18 \mathrm{~S}, \mathrm{I}\end{array}$ & $356 \times 368 \times 153 \cup C$ & W14X61 & W14X48 & W14X53 & W18X46 & W14X43 & W14X61 & W24X55 \\
\hline 19 & $\begin{array}{c}\text { Column } \\
19-21 \mathrm{~S}, \mathrm{I}\end{array}$ & $203 \times 203 \times 60 U C$ & W14X30 & W14X30 & W14X38 & W18X35 & W14X34 & W14X26 & W24X55 \\
\hline 20 & $\begin{array}{l}\text { Column } \\
21-24 S, I\end{array}$ & $254 X 254 X 89 \cup C$ & W14X26 & W14X22 & W14X26 & W16X31 & W14X22 & W14X22 & W10X12 \\
\hline $\begin{array}{l}\text { Weight } \\
(\mathrm{kN})\end{array}$ & & 958.75 & 980.63 & 955.74 & 967.33 & 884.88 & 945.2 & 925.64 & 877.22 \\
\hline
\end{tabular}




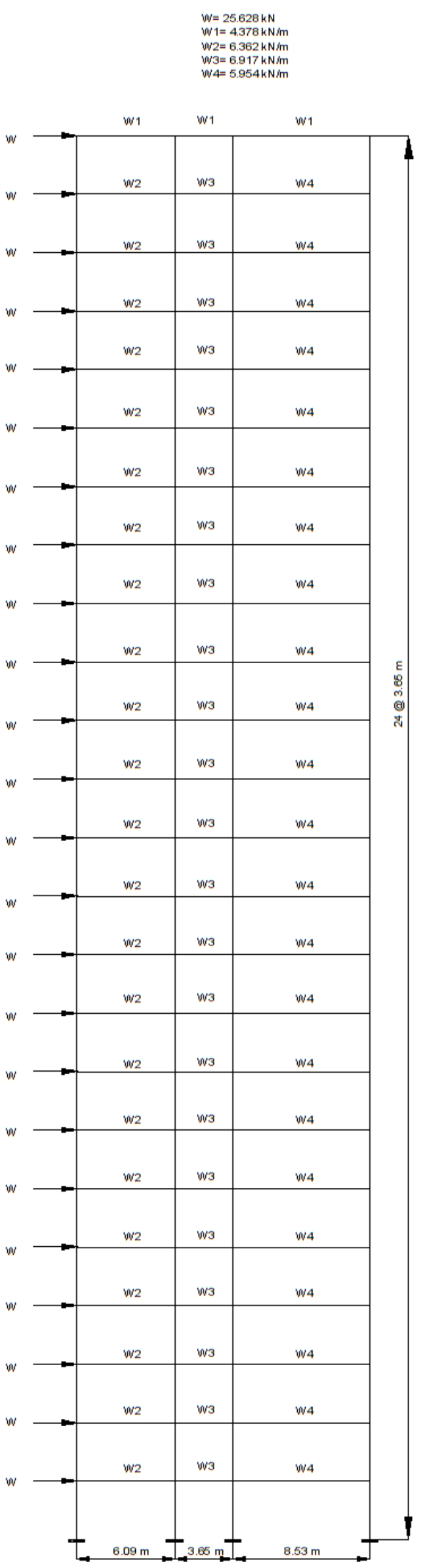

Fig. 8. A 3-bay 24-story frame

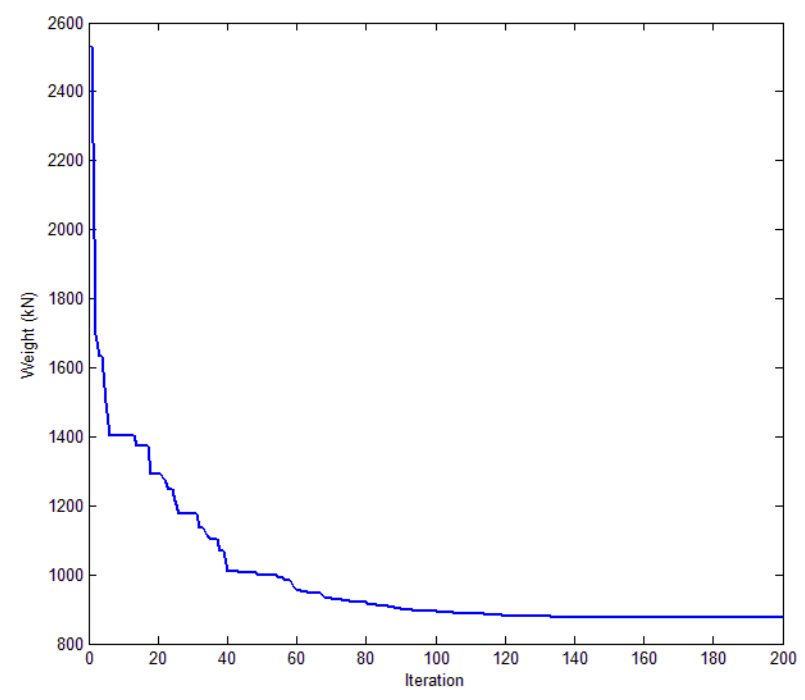

Fig. 9. Convergence curve of the best run for the 3-bay 24-story frame (Case 1)

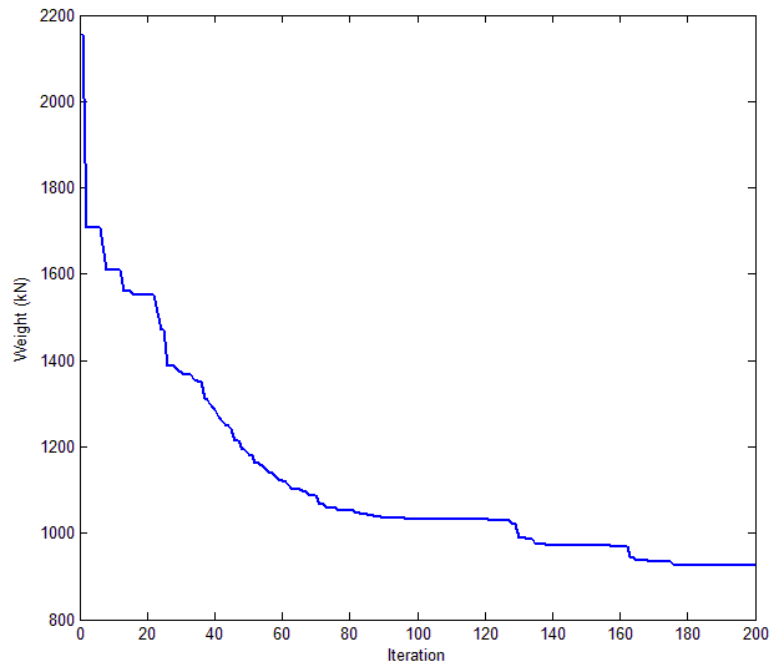

Fig. 10. Convergence curve of the best run for the 3-bay 24-story frame (Case 2)

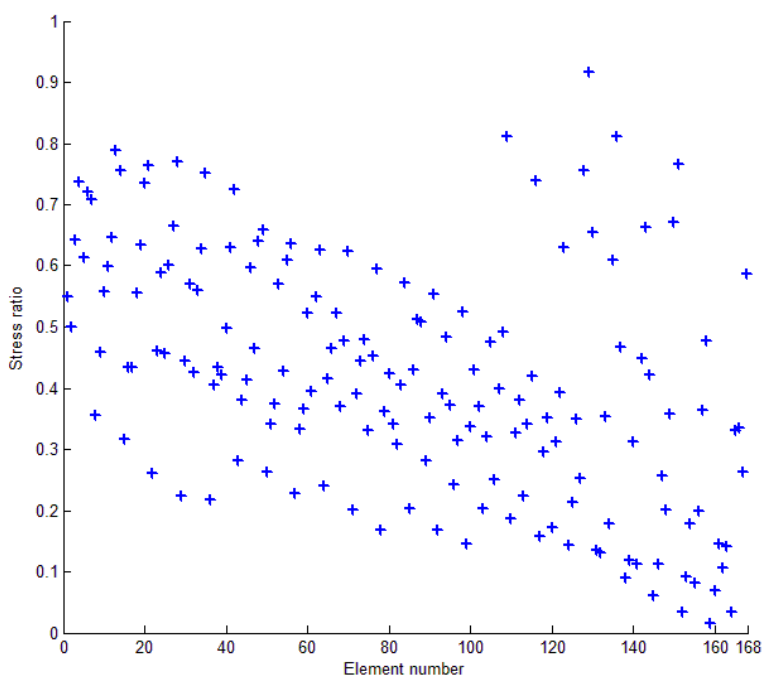

Fig. 11. Stress ratios of the members for the 3-bay 24-story frame (Case 1) 


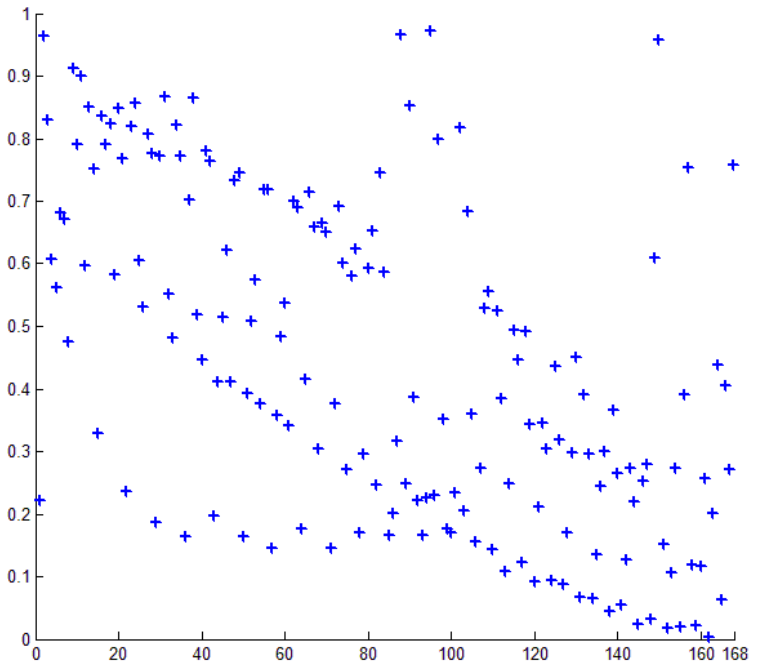

Fig. 12. Stress ratios of the members for the 3-bay 24-story frame (Case 2)

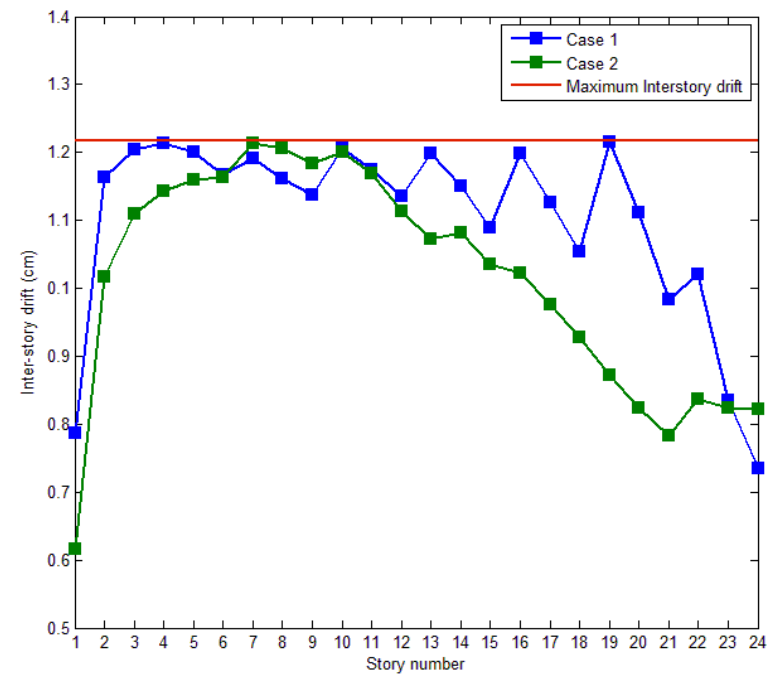

Fig. 13. Inter-story drifts of the optimal structures in Cases 1 and 2

\section{References}

1 Holland J, Adaptation in Natural and Artificial Systems, University of Michigan Press, 1975.

2 Goldberg D, Genetic Algorithms in Search Optimization and Machine Learning, Addison-Wesley, 1989.

3 Eberhart R, Kennedy J, A new optimizer using particle swarm theory, Sixth International Symposium on Micro Machine and Human Science, In:, 1995, pp. 39-43.

4 Dorigo M, Maniezzo V, Colorni A, Ant system: optimization by a colony of cooperating agents, IEEE Transactions on Systems, Man and Cybernetics, Part B (Cybernetics), 26(1), (1996), 29-41, DOI $10.1109 / 3477.484436$

5 Kirkpatrick S, Gelatt C, Vecchi M, Science, 220(4598), (1983), 671-680, DOI $10.1126 /$ science.220.4598.671

6 Geem Z, Kim J, Loganathan G, A New Heuristic Optimization Algorithm: Harmony Search, Simulation, 76(2), (2001), 60-68, DOI 10.1177/003754970107600201

7 Rashedi E, Nezamabadi-pour H, Saryazdi S, Information Sciences, 179(13), (2009), 2232-2248, DOI 10.1016/j.ins.2009.03.004

8 Erol O, Eksin I, A new optimization method: Big Bang-Big Crunch, Advances in Engineering Software, 37(2), (2006), 106-111, DOI 10.1016/j.advengsoft.2005.04.005
9 Kaveh A, Talatahari S, Size optimization of space trusses using Big Bang-Big Crunch algorithm, Computers \& Structures, 87(17-18), (2009), 1129-1140, DOI 10.1016/j.compstruc.2009.04.011

10 Kaveh A, Laknejadi K, Alinejad B, Performance-based multi-objective optimization of large steel structures, Acta Mechanica, 223(2), (2012), 355369, DOI 10.1007/s00707-011-0564-1

11 Kaveh A, Talatahari S, Charged system search for optimal design of frame structures, Applied Soft Computing, 12(1), (2012), 382-393, DOI 10.1016/j.asoc.2011.08.034

12 Kaveh A, Talatahari S, Particle swarm optimizer, ant colony strategy and harmony search scheme hybridized for optimization of truss structures, Computers \& Structures, 87(5-6), (2009), 267-283, DOI 10.1016/j.compstruc.2009.01.003

13 Kaveh A, Talatahari S, Optimization of large-scale truss structures using modified charged system search, International Journal of Optimization in Civil Engineering, 1(1), (2011), 15-28.

14 Kaveh A, Zolghadr A, Topology optimization of trusses considering static and dynamic constraints using the CSS, Applied Soft Computing, 13(5), (2013), 2727-2734, DOI 10.1016/j.asoc.2012.11.014

15 Kaveh A, Zolghadr A, Comparison of nine meta-heuristic algorithms for optimal design of truss structures with frequency constraints, Advances in Engineering Software, 76, (2014), 9-30, DOI 10.1016/j.advengsoft.2014.05.012

16 Kaveh A, Zolghadr A, A multi-set charged system search for truss optimization with variables of different natures; element grouping, Periodica Polytechnica Civil Engineering, 55(2), (2011), 87-98, DOI 10.3311/pp.ci.2011-2.01

17 Csébfalvi A, A hybrid meta-heuristic method for continuous engineering optimization, Periodica Polytechnica Civil Engineering, 53(2), (2009), 93100, DOI 10.3311/pp.ci.2009-2.05

18 Csébfalvi A, Multiple constrained sizing-shaping truss-optimization using ANGEL method, Periodica Polytechnica Civil Engineering, 55(1), (2011), 81-86, DOI 10.3311/pp.ci.2011-1.10

19 Kaveh A, Talatahari S, A novel heuristic optimization method: charged system search, Acta Mechanica, 213(3-4), (2010), 267-289, DOI 10.1007/s00707-009-0270-4

20 Kaveh A, Motie Share M, Moslehi M, Magnetic charged system search: a new meta-heuristic algorithm for optimization, Acta Mechanica, 224(1), (2013), 85-107, DOI 10.1007/s00707-012-0745-6

21 Manual of steel construction Load resistance factor design, 3th, American Institute of Steel Construction (AISC); Chicago (IL), 2001.

22 Dumonteil P, Simple equations for effective length factors, Engineering Journal (AISC), 29(3), (1992), 111-115.

23 Grandhi R, Venkayya V, Structural optimization with frequency constraints, AIAA Journal, 26(7), (1988), 858-866, DOI 10.2514/3.9979

24 Sedaghati R, Suleman A, Tabarrok B, Structural Optimization with Frequency Constraints Using the Finite Element Force Method, AIAA Journal, 40(2), (2002), 382-388, DOI 10.2514/2.1657

25 Wang D, Zhang W, Jiang J, Truss Optimization on Shape and Sizing with Frequency Constraints, AIAA Journal, 42(3), (2004), 622-630, DOI 10.2514/1.1711

26 Lingyun W, Mei Z, Guangming W, Guang M, Truss optimization on shape and sizing with frequency constraints based on genetic algorithm, Computational Mechanics, 35(5), (2005), 361-368, DOI 10.1007/s00466004-0623-8

27 Gomes M, Truss optimization with dynamic constraints using a particle swarm algorithm, Expert Systems with Applications, 38(1), (2011), 957968, DOI 10.1016/j.eswa.2010.07.086

28 Kaveh A, Zolghadr A, Shape and size optimization of truss structures with frequency constraints using enhanced charged system search algorithm, Asian Journal of Civil Engineering, 12(4), (2011), 487-509. 
29 Kaveh A, Zolghadr A, Truss optimization with natural frequency constraints using a hybridized CSS-BBBC algorithm with trap recognition capability, Computers \& Structures, 102-103, (2012), 14-27, DOI 10.1016/j.compstruc.2012.03.016

$30 \mathbf{W u}$ S, Chow P, Steady-state genetic algorithms for discrete optimization of trusses, Computers \& Structures, 56(6), (1995), 979-991, DOI 10.1016/0045-7949(94)00551-D

31 Li L, Huang Z, Liu F, A heuristic particle swarm optimization method for truss structures with discrete variables, Computers \& Structures, 87(7-8), (2009), 435-443, DOI 10.1016/j.compstruc.2009.01.004

32 Kaveh A, Talatahari S, A particle swarm ant colony optimization for truss structures with discrete variables, Journal of Constructional Steel Research, 65(8-9), (2009), 1558-1568, DOI 10.1016/j.jcsr.2009.04.021

33 Manual of steel construction allowable stress design, 9th, American Institute of Steel Construction (AISC); Chicago (IL), 1989.

34 Khot N, Venkayya V, Berke L, Optimum structural design with stability constraints, International Journal for Numerical Methods in Engineering, 10(5), (1976), 1097-1114, DOI 10.1002/nme.1620100510

35 Camp C, Pezeshk S, Cao G, Optimized Design of Two-Dimensional Structures Using a Genetic Algorithm, Journal of Structural Engineering, 124(5), (1998), 551-559, DOI 10.1061/(ASCE)0733-9445(1998)124:5(551)

36 Kaveh A, Shojaee S, Optimal design of skeletal structures using ant colony optimization, International Journal for Numerical Methods in Engineering, 70(5), (2007), 563-581, DOI 10.1002/nme.1898

37 Kaveh A, Talatahari S, An improved ant colony optimization for the design of planar steel frames, Engineering Structures, 32(3), (2009), 864-873, DOI 10.1016/j.engstruct.2009.12.012

38 Davison J, Adams P, Stability of braced and unbraced frames, Journal of Structural Division, ASCE, 100(2), (1974), 319-334.

39 Saka M, Kameshki E, Optimum design of multi-story sway steel frames to BS 5950 using a genetic algorithm, Topping BHV, editor, Advances in Engineering Computational Technology, Civil-Camp Press, In:, 1998, pp. 135141.

40 British Standards, BS 5950, Structural use of steelworks in building, Part 1 Code of practice for design in simple and continuous construction, hot rolled sections, British Standard Institution; London, 1990.

41 Camp C, Bichon J, Stovall S, Design of steel frames using ant colony optimization, Journal of Structural Engineering (ASCE), 131(3), (2005), 369379, DOI 10.1061/(ASCE)0733-9445(2005)131:3(369)

42 Kaveh A, Talatahari S, Charged System Search for Optimal Design of Frame Structures, Applied Soft Computing, 12(1), (2012), 382-393, DOI 10.1016/j.asoc.2011.08.034

43 Degertekin S, Optimum design of steel frames using harmony search algorithm, Structural and Multidisciplinary Optimization, 36(4), (2008), 393 401, DOI 10.1007/s00158-007-0177-4 